\title{
A Case Study on the Pattern of Classroom Discourse in Teaching Chinese as a Foreign Language
}

\author{
Liqing Li* \\ Zhanjiang University of Science and Technology, Zhanjiang 524094, Guangdong Province, China \\ *Corresponding author: Liqing Li, 374284686@qq.com
}

\begin{abstract}
Based on the IRF (initiation, response, and feedback) classroom discourse structure model proposed by Sinclair and Coulthard, this research analyzes and studies the actual corpus of Chinese classroom teaching in Thailand, focusing on the structural model of teacher-student communication discourse, mainly from two aspects of teachers' feedback. On the one hand, it investigates whether IRF is fully applicable to Chinese classroom teaching and whether there are special situations to it. On the other hand, it attempts to summarize the discourse structure model of Chinese classroom teaching and explores the application of the research results in helping Chinese teachers improve their teaching quality in hope that constructive suggestions can be proposed for teaching Chinese as a foreign language.
\end{abstract}

Keywords: IRF model; Classroom discourse structure; Teachers' feedback; Chinese as a foreign language classroom

Publication date: October 2021; Online publication: October 29, 2021

\section{Introduction}

With the development of Chinese international education, teaching Chinese as a foreign language has been greatly promoted. Chinese has been revealed to the world and is recognized by people from all over the world. However, there are new requirements for the development of the discipline and the training of teachers. In teaching Chinese as a foreign language, teaching materials, teaching methods, and teachers have become the three teaching problems, among which teachers have become the top priority. Teachers play a leading role in teaching Chinese as a foreign language. They are the main figure of the whole teaching process and the key factor affecting the teaching effect. Classroom teaching is a stage for teachers to display their knowledge, skills, literacy, and wisdom. Classroom discourse is an important link for second language learners to learn Chinese ${ }^{[1]}$. Therefore, the research on the classroom discourse model does not only put forward effective suggestions for the training of teachers, but also assist second language learners to learn Chinese more efficiently as well as promote the development of Chinese international education.

The research on classroom discourse analysis began abroad in the 1940s and developed rapidly in the 1960s. In The Language of the Classroom, written by Bellack in 1966, teacher-pupil interactions are divided into four steps: structure, solicit, response, and react. From that, he became the founder of classroom discourse analysis. Sinclair and Coulthard proposed the IRF classroom discourse model on this basis; that is, teachers' initiation, students' response, and teachers' feedback. It had a significant impact on later research on the classroom discourse model by other scholars. In 1976, Metear proposed the structure of $\operatorname{IRF}\left(R^{\prime}\right)$ on the basis of IRF; Metear suggested that students would sometimes add a response after receiving feedback from teachers. 
In researching on classroom discourse patterns, local researchers mostly focus on the field of foreign language teaching, especially English classroom teaching. For example, Yuee Li suggested the existence of four discourse patterns in local English classroom teaching [2]; Xueyan Yang discussed the practical significance of classroom discourse research in a foreign language classroom environment and its theoretical significance in the field of foreign language teaching and second language acquisition [3]; Xiangguo Zhang conducted a study on classroom discourse analysis of English teachers in independent

colleges ${ }^{[4]}$. However, there are only a few studies on classroom discourse structure model of teaching Chinese as a foreign language. Based on the retrieved literatures, they include Yunxia Li's research on discourse interaction in teaching Chinese as a foreign language and Min Lei's research on novice Chinese teachers. Although the research is on Chinese classroom teaching, it emphasizes more on teachers' language input, teacher-student classroom interactions, and so on. There are only a few research on the model of classroom discourse structure.

\section{Structural model of classroom discourse}

IRF classroom discourse structure model was proposed by Sinclair and Coulthard in 1975. It mainly studies the structural model of teacher-pupil dialogue in the process of classroom teaching, including the discourse function, sentence sequence, and turn substitution. IRF classroom discourse structure model refers to initiation $(\mathrm{I}) \rightarrow$ response $(\mathrm{R}) \rightarrow$ feedback $(\mathrm{F})$; that is, teachers' initiation, students' response, and teachers' feedback. After the emergence of this model, many scholars have discussed and concluded that this model is not completely applicable to all classroom teaching but only to the traditional teacher-led classroom interaction, which is authoritative and cooperative ${ }^{[2]}$. Sinclair and Coulthard added that this model does not work in group discussions or during games; rather, it is just a prototype. Therefore, the key content of this study is to observe the structural model of communication discourse between teachers and students. The soliloquy of teacher-student interaction, practice between students and students, role play, and other classroom activities are not within the scope of this study.

\subsection{Source of corpus and research subject}

In this case study, 23 sophomores from the Bilingual Department of Huachiew Chalermprakiet University in Thailand (intermediate level in Chinese) and 28 Senior Two students from Samut Prakan Business Vocational and Technical College in Thailand (basic level in Chinese) were selected. The types of classes for the sophomores and Senior Two students are comprehensive classes and basic oral classes, respectively. Two classes were recorded in their natural state; each class lasted for 40 minutes, with 160 minutes in total. In this way, the corpus was obtained in a natural state as the observer did not know of the purpose in advance. The teacher involved is a novice teacher with only a year of experience in teaching. By watching the videos, the observer translated the dialogues shared between the teacher and the students from four class hours into a corpus, with about 20,000 words.

\subsection{Analysis based on the IRF discourse structure model proposed by Sinclair and Coulthard}

The IRF classroom discourse structure model mentioned above refers to three aspects: teachers' initiation, students' response, and teachers' feedback. These three steps constitute a teaching round, and each round constitutes a class segment. How then to distinguish the boundary between class segments? This involves the concept of boundary rounds. A boundary round marks the end of one lesson and the beginning of another. It comprises of a frame step and a focus step. It is generally marked by "good," "okay," "let's see again," and other connecting terms ${ }^{[5]}$. However, this study focuses on analyzing the teaching round without considering the boundary round. These concepts are clarified by analyzing the example below: 


\section{Example 1}

Teacher : Come on, let's look at the answer above. // The first question, "Where's your book?". How should you answer?

Student : My book was borrowed by my classmates.

Teacher : My book was borrowed by a classmate. // You should use the above example sentence to complete, but this sentence is also correct, depending on the title. // Next, the second question, "Why don't you use your own computer?"

Student $\quad$ : I made the computer ...

Teacher : It's broken. I broke the computer. //

Note: The corpus is from the course of sophomores in Huachiew Chalermprakiet University, Thailand

In the above example, the teacher's first sentence, "Come on, let's look at the answer above" and the teacher's second step, "Next, second, the second question," constitute a boundary round. From the first symbol of "///" to the second symbol of "//" is a teaching round, and from the third symbol of "//" to the fourth symbol of "///" is another teaching round. The teacher asks a question, the student answers, and then the teacher provides feedback. Each process is a conversation step ${ }^{[6]}$. Here, the initiation step, response step, and feedback step are denoted clearly, forming a teaching round.

According to the analysis of the collected corpus, we find that not every teaching round is in line with the IRF discourse structure model proposed by Sinclair and Coulthard, whether it involves the Senior Two students with basic Chinese level or sophomores with intermediate Chinese level. At times, there are special situations such as IRF(R'), IR, I-I-R-F, IR-IR-IR-F, etc.

\subsection{Supplementing the IRF discourse structure model by Metear}

In the introduction, it was mentioned that Metear supplemented the IRF discourse structure model and proposed the $\operatorname{IRF}\left(\mathrm{R}^{\prime}\right)$ structure, which has been proven in a research by Yuee Li. This structure is verified below through the collected corpus:

\section{Example 2}

Teacher : Okay, I will now ask a few students to answer my question? What do you usually drink for breakfast?

Student 1 : I drink water for breakfast.

Teacher : What does he have for breakfast?

Student 2 : He drinks water for breakfast.

Teacher : Good, very good, he drinks water for breakfast.

Student : He drinks water for breakfast.

Teacher : Okay, you, what do you usually have for breakfast?

Student 3 : I have coffee for breakfast.

Teacher : What does she usually have for breakfast?

Student 4 : She usually has coffee for breakfast.

Teacher : Okay, she has coffee for breakfast.

Student : She has coffee for breakfast.

Note: The corpus is derived from the oral English class of Senior Two students in Samut Prakan Business Vocational and Technical College

Through the above Example 2, it can be appreciated that when the teacher give positive feedbacks to the students' responses, students unconsciously imitate or repeat the teacher's feedback. This is what 
Metear and Yuee Li suggested, where students would add a "reflection" at times. This view has been recognized by many scholars. Therefore, the IRF discourse structure model can be revised to IRF(R'), i.e., initiation step $\rightarrow$ response step $\rightarrow$ feedback step $\rightarrow$ (response step) ${ }^{[7]}$.

\subsection{Summary}

Based on the IRF discourse structure model, through the analysis of the corpus, the basic IRF discourse structure model can be enriched into four models.

(1) $\operatorname{IRF}\left(R^{\prime}\right)$ model: Initiation step $\rightarrow$ response step $\rightarrow$ feedback step $\rightarrow$ (response step)

(2) When a teacher's initiation is not responded in time, the following models can be used: $\mathrm{I}_{1}-\mathrm{I}_{2} \ldots \mathrm{I}_{\mathrm{N}}-\mathrm{R}-\mathrm{F}$ model: Initiation step $1 \rightarrow$ initiation step $2 \ldots \rightarrow$ response step $\rightarrow$ feedback step $\mathrm{I}(\mathrm{R}) \mathrm{F}$ model: Question / instruction (initiation) step $\rightarrow$ (response step) $\rightarrow$ feedback step

(3) Teachers' re-initiation

IR $\left[\mathrm{I}_{1} \mathrm{R}_{1}\left(\mathrm{I}_{2} \mathrm{R}_{2}\left(\mathrm{I}_{3} \mathrm{R}_{3}\left(\mathrm{I}_{\mathrm{N}} \mathrm{R}_{\mathrm{N}}\right)\right]\right.\right.$ model: Initiation $\rightarrow$ response $\rightarrow$ [re-initiation ${ }_{1} \rightarrow$ re-response ${ }_{1} \ldots$ reinitiation $_{\mathrm{n}} \rightarrow$ re-response $\left.\mathrm{n}\right] \rightarrow$ feedback

(4) Students respond actively, but teachers do not provide feedback

$\mathrm{IR}(\mathrm{F})$ mode: Initiation step $\rightarrow$ response step $\rightarrow$ (feedback step)

Most of the corpora collected are in line with the above four structural patterns. According to preliminary statistics, there are about 23 corpora in line with $\operatorname{IRF}\left(\mathrm{R}^{\prime}\right)$ model. However, it has been found that $\operatorname{IRF}\left(\mathrm{R}^{\prime}\right)$ and $\mathrm{IR}(\mathrm{F})$ occurred more frequently in the Senior Two classes compared to the sophomore classes. The models in (2) and (3) occurred more frequently in sophomore classes compared to Senior Two classes ${ }^{[3]}$. This may be related to the students' proficiency level. For students with higher Chinese proficiency, the teacher focused more on guiding students to think by asking questions, while for students with lower proficiency, the teacher focused on explaining and repeating information.

Is it possible for these four discourse structure models to be summarized as the IRF discourse structure model? Sinclair and Coulthard admitted that the proposed IRF discourse structure model is only a prototype and does not have universal significance, so it can be enriched and supplemented. These four discourse structure models also meet the basic structure model of IRF. Although an initiation may not receive a timely response through speech, the silence among students is also a response strategy to the question. The silence may indicate, "We do not know this question," or "We do not understand this question" "4]. On the contrary, it is also true that teachers do not provide feedback to students' responses. Therefore, it can be concluded that the IRF discourse structure model proposed by Sinclair and Coulthard sometimes cannot completely describe the classroom discourse structure.

\section{Enlightenment to teaching}

Through the analysis of the collected corpus, it has been found that most of these discourse structure patterns occur in teacher-led classroom teaching, where teachers are in control of the whole conversation, while students are seated over the passive side. The time to respond and the person who should respond are strictly controlled by teachers. Teachers are always asking questions, setting questions, and controlling the development direction of a topic. Therefore, such a classroom discourse structure model is relatively closed in view of the traditional teaching method. This is not conducive to the cultivation of divergent thinking among students. Therefore, a few suggestions on teacher-student conversation in teaching Chinese as a foreign language have been proposed. 


\subsection{Diversify the questions}

In selecting or setting questions, teachers should ensure that the questions asked would lead to unique answers and divergent thinking. They should select questions with moderate difficulty and choose topics that students are interested in to ask questions. This would effectively stimulate students' enthusiasm to actively participate during lessons. Students should be the main body of the classroom and rather than blindly accepting information, they should be encouraged to think independently, ask questions bravely, and express their views, in order to cultivate their thinking, desire to express, and critical consciousness ${ }^{[8]}$. At the same time, teachers should try to create an active and positive classroom environment before asking questions. This would be more conducive to students' divergent thinking.

\subsection{Appropriate feedbacks}

When students respond correctly, teachers should provide encouraging feedbacks and leave some time for students to supplement and improve their answers. However, if students are not able to respond well, teachers should prompt them without attacking their enthusiasm and allow them to consciously correct their answers by means of re-initiating. Teachers' feedback can also be in the form of asking progressive questions to guide students in correcting their answers step by step ${ }^{[9]}$. Feedbacks from teachers should take into consideration of the thoughts and feelings of the students, so that students would be able to accept them psychologically, rather than offering a superficial response.

\subsection{No interruption policy}

When students initiate problems, teachers should pay attention to them without interrupting their questions. It is best to start from students' questions and provide feedbacks. This is more conducive to broaden students' thinking and enable them to produce more language output.

\subsection{Interpersonal relationship harmony}

During conversations between teachers and students, teachers would imperceptibly affect students' communicative competence. Therefore, teachers should emphasize on maintaining the harmony in interpersonal relationships with the students during lessons.

\section{Conclusion}

Based on the IRF classroom discourse structure model proposed by Sinclair and Coulthard, this study analyzes the actual corpus of Chinese classroom teaching in Thailand, focusing on the structural model of teacher-student communication, mainly from two aspects of teachers' feedback. On the one hand, it investigates whether IRF is fully applicable to Chinese classroom teaching and whether there are special situations for it. On the other hand, it attempts to summarize the discourse structure model of Chinese teaching classroom and explore the application of the research results in helping Chinese teachers improve their teaching quality in hope to propose constructive suggestions for teaching Chinese as a foreign language ${ }^{[10]}$.

Certainly, there are still many deficiencies in this study. Due to limited ability, this study was unable to carry out a large-scale investigation and research. In addition, the collected corpus is specific only to a special case, which does not represent the general situation and may not be universal. Therefore, this research on the structural model of classroom discourse is only an attempt, and there are still many aspects that need further discussion. 


\section{Disclosure statement}

The author declares that there is no conflict of interest.

\section{References}

[1] Lu Y, 1996, Birmingham School Discourse Analysis and Its Development. Foreign Languages Research, (4): 6-12.

[2] Li Y, Fan HY, 2002, Discourse Analysis, Shanghai Foreign Language Education Press, Shanghai.

[3] Yang XY, 2003, Study on Classroom Strategies of Foreign Language Teachers: Status and Significance. Foreign Language Teaching and Research, (1): 12-14.

[4] Zhang XG, 2011, A Case Study of Classroom Discourse Analysis for Independent College English Teachers. Journal of Foreign Languages, (42): 272-273.

[5] Chen XY, 2005, Analysis of Chinese Classroom Discourse Pattern and Its Teaching Enlightenment. Jinan University.

[6] Cheng XT, 2009, Analysis of English Teachers' Classroom Discourse, Shanghai Foreign Language Education Press, Shanghai.

[7] Peng J, 2013, Research Overview of Domestic Classroom Discourse Analysis in the Past 20 Years. Journal of Yichun University, (4): 124-128.

[8] Cui SD, 2000, A Study on the Characteristics and Functions of Questioning Language in Teaching. Applied Linguistics, (4): 28-33.

[9] Chen Q, 2004, Teacher Discourse, Classroom Role and Language Learning. Journal of Sichuan Normal University, (4): 82-86.

[10] Hao L, 2003, A Survey of Communicative Language Use by TCSL Teachers and Chinese Learners. Journal of College of Chinese Language and Culture of Jinan University, (2) 27-34. 